\title{
The Drosophila segment polarity gene dishevelled encodes a novel protein required for response to the wingless signal
}

\author{
John Klingensmith, ${ }^{1,2}$ Roel Nusse, ${ }^{2}$ and Norbert Perrimon ${ }^{1}$ \\ ${ }^{1}$ Howard Hughes Medical Institute, Department of Genetics, Harvard Medical School, Boston, Massachusetts 02115 USA; \\ ${ }^{2}$ Howard Hughes Medical Institute, Department of Developmental Biology, Stanford University School of Medicine, \\ Stanford, California 94305 USA
}

The Drosophila Wnt-1 homolog, wingless $(\mathrm{wg})$, is involved in the signaling of patterning information in several contexts. In the embryonic epidermis, $\mathrm{Wg}$ protein is secreted and taken up by neighboring cells, in which it is required for maintenance of engrailed transcription and accumulation of Armadillo protein. The dishevelled (dsh) gene mediates these signaling events as well as wg-dependent induction across tissue layers in the embryonic midgut. $d s h$ is also required for the developmental processes in which wg functions in adult development. Overall, cells lacking $d s h$ are unable to adopt fates specified by Wg. $d s h$ functions cell autonomously, indicating that it is involved in the response of target cells to the $\mathrm{Wg}$ signal. $d s h$ is expressed uniformly in the embryo and encodes a novel protein with no known catalytic motifs, although it shares a domain of homology with several junction-associated proteins. Our results demonstrate that $d s h$ encodes a specific component of $\mathrm{Wg}$ signaling and illustrate that Wnt proteins may utilize a novel mechanism of extracellular signal transduction.

[Key Words: Drosophila; wingless; dishevelled; signal transduction]

Received September 16, 1993; revised version accepted November 23, 1993.

By the time the Drosophila embryo becomes cellularized, the segmented body pattern has been established. Organization within the segment itself occurs via interactions among its nascent cells. Some 15 genes have been identified that are required for this initial intrasegmental patterning, known as segment polarity genes, many of which have maternal as well as zygotic contributions (for review, see Klingensmith and Perrimon 1991; Peifer and Bejsovec 1992).

The cuticle defects of segment polarity mutants are largely the result of abnormal cell interactions occurring much earlier. For example, the most posterior cells of the segment, which express engrailed (en) and secrete either denticle or naked cuticle, are instructed by signals from their neighbors to the anterior, which express wingless (wg) (Bejovec and Martinez-Arias 1991; Dougan and DiNardo 1992). wg, the Drosophila homolog of the secreted murine oncoprotein Wnt-1 (Rijsewijk et al. 1987), appears to directly promote the cell fate of naked cuticle secretion in that ubiquitously expressed $w g$ results in an entirely naked cuticle (Noordermeer et al. 1992). This observation also reveals that not only the en domain but also cells in the anterior of the segment, which normally secrete denticles, can respond to the wg-dependent cell fate signal.
The earliest known cell interaction leading to segmental patterning also involves communication between the $w g$ and en domains, but in this case the purpose is for mutual maintenance of expression. Although the initial expression of $w g$ and $e n$ in adjacent stripes is directed by the pair-rule genes, maintenance of $w g$ and en expression requires the function of the other gene in the adjacent cells (DiNardo et al. 1988; Martinez-Arias et al. 1988).

The signal from the wg domain that acts to maintain en expression is thought to be $\mathrm{Wg}$ itself. Electron microscopy of sections of embryos stained with anti-Wg antibodies reveals that $\mathrm{Wg}$ is secreted by those cells that express it and is taken up by surrounding cells. Doublelabeling experiments indicate that $\mathrm{Wg}$ antigen can be detected inside en-expressing cells (van den Heuvel et al. 1989; Gonzalez et al. 1991). In addition, maintenance of en expression in purified, cultured cells of the en domain requires the presence of cocultured $w g$ transfectant cells (Cumberledge and Krasnow 1993). These results are consistent with the nonautonomous behavior of $w g$ mutant clones in adult structures (Morata and Lawrence 1977; Babu and Bhat 1986; Baker 1988a).

The molecular mechanism by which wg signals is unknown. Moreover, although Wnt homologs in many 
other species and in cell culture systems appear to encode paracrine cell fate signals, in no case is there any information on the molecular pathway of Wnt signal transduction (for review, see Nusse and Varmus 1992). Candidates for genes involved in wg signaling in the embryonic epidermis are the other segment polarity genes, especially those resulting in a mutant cuticle phenotype like that of $w g$. Based on similarity of phenotypes and time course of En decay, the maternal-effect segment polarity genes armadillo (arm) (Klingensmith et al. 1989; Peifer et al. 1991), dishevelled (dsh) and porcupine (Klingensmith and Perrimon 1991; van den Heuvel et al. 1993a) may encode components of the wg pathway. arm, a catenin-like junction protein (Peifer et al. 1992), is a target of $w g$ signaling, in that wg directs post-transcriptional accumulation of Arm protein in cells including and flanking the wg stripe (Riggleman et al. 1990). This effect of wg was evaluated in various segment polarity mutant backgrounds, and $d s h$ appears to be an essential requirement. Similarly, we have shown that $d s h$ is necessary for the effects of ubiquitous $w g$ expression on segmentation (Noordermeer et al. 1994). dsh therefore seems a likely candidate for a gene encoding a component of the wg signaling pathway.

We have examined the roles of $d s h$ in patterning of the embryonic epidermis and in other contexts in which wg is known to function and conclude that $d s h$ is required for proper cell fate in wg-responsive tissue. We have analyzed the cellular requirement, molecular structure, and expression of $d s h$ and propose that $d s h$ represents a novel signal transduction molecule generally required for the response of target cells to the Wg signal.

\section{Results}

\section{dsh mediates the effects of $\mathrm{wg}$ in the embryo}

Although $d s h$ is expressed both maternally and zygotically, either the maternal or the zygotic component is sufficient to permit normal embryonic development (Perrimon and Mahowald 1987; Fig. 1A). When both components are lacking, $d s h$ embryos display patterning defects identical to those of $w g$ null mutants (Fig. 1B,C), from the earliest stage (11) at which morphological defects can be detected (Perrimon and Mahowald 1987). We refer to embryos lacking both maternal and zygotic contributions as $d s h$ embryos.

Wg signaling in the ventral epidermis The timing of disappearance of En antigen in $d s h$ embryos is identical to that observed in wg embryos (van den Heuvel et al. 1993a); however, the role of other genes in the maintenance of $e$ expression by $w g$ is difficult to study because $e n$ in turn is required for maintenance of $w g$ expression (Martinez-Arias et al. 1988). Thus in $d s h$ embryos, we have found that En and Wg staining patterns are initially normal but both antigens disappear during extended germ-band stages. To address directly which antigen disappears first, and thus what aspect of the loop $d s h \mathrm{mu}-$ tants affect most directly, we double-stained $d s h$ em-
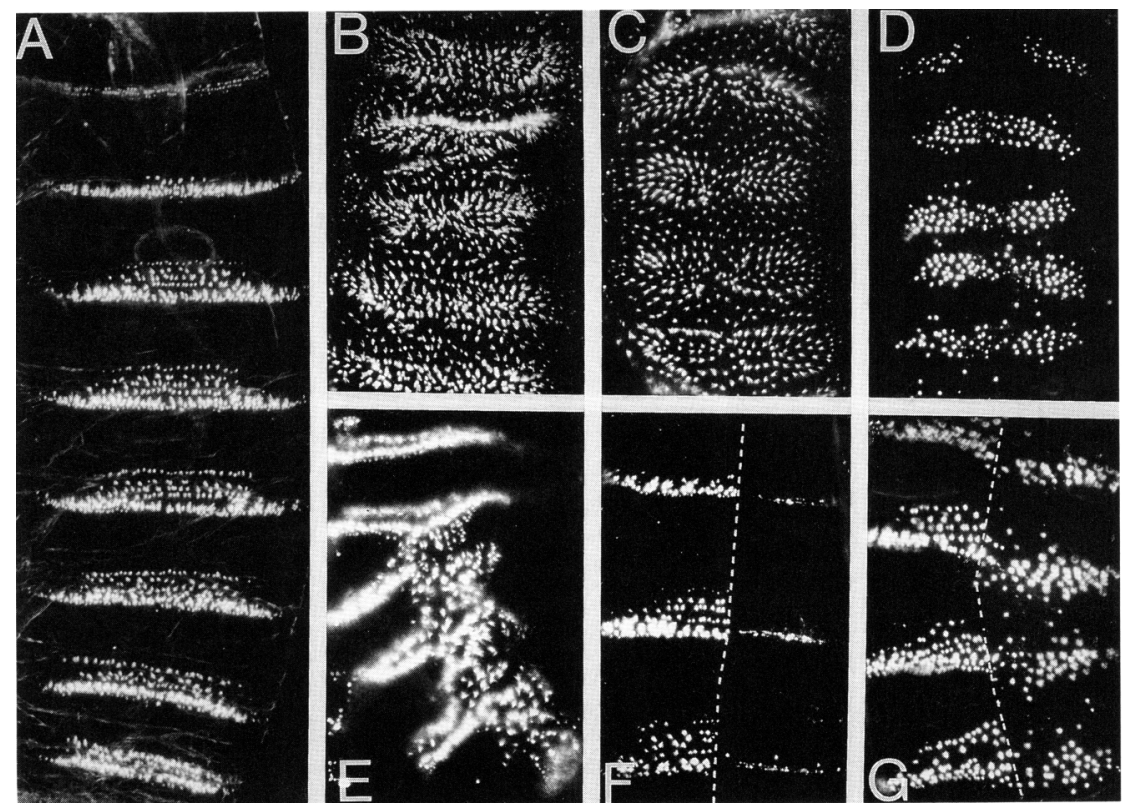

Figure 1. Embryonic phenotype and autonomy of $d s h$. Cuticles of terminally differentiated embryos are shown in darkfield (ventral views; anterior is up). $(A)$ Wild-type $(d s h /+)$ larva, early first instar. A denticle belt spans the anterior portion of each segment, with the tips of denticles in most rows being aligned toward the posterior. Posterior cells secrete naked cuticle. Note that $w g$ and $d s h$ embryos are less than half the length of their wild-type siblings. $(B) d s h^{v 26}$ embryo. Denticles form an irregular lawn without naked cuticle, with many lateral denticles oriented toward the midline. Note that no segment borders form to define segments. These embryos also lack the filzkörper structure at the posterior and are missing all head structures. $(C) w^{C X 4} / w^{C X 4}$ embryo. The embryo displays the same phenotypes as the dsh mutant. (D) $s v b, d s h^{v 26}$ embryo. The $s v b$ mutation reduces the number and size of denticles, further revealing the metameric pattern of denticles persisting

in this phenotype. (E) dsh ${ }^{M 20} /$ ring-X mosaic embryo. Mosaicism is indicated by filzkörper material (not in focus), with a patch of denticles displaying the $d s h$ phenotype (lower right quadrant). This pattern is sharply demarcated from the adjacent wild-type pattern, suggesting lack of rescue by adjacent wild-type tissue; however, the exact border cannot be determined because the mutant tissue is not marked. $(F) s v b /$ ring- $X$ mosaic embryo. $s v b$ denticles occur in a wild-type pattern, with no effect on the adjacent wild-type denticles (left of dotted line). (G) svb,dsh ${ }^{v 26} /$ ring- $X$ mosaic embryo. The mutant side of the embryo (right) displays a segment polarity phenotype identical to that of $s v b, d s h$ alone (cf. $D$ ). Wild-type denticles (left) are unaffected. 
bryos with Wg and En antibodies. We examined the expression of these antigens during stages 9-11 in which en expression is dependent on $\mathrm{Wg}$ (Heemskerk et al. 1991). In late stage $9 d s h$ embryos, En expression has largely deteriorated while $\mathrm{Wg}$ antigen appears wild type (data not shown). Wg antigen persists in $d s h$ until mid-stage 10 , at which time it also begins to disappear in en mutants (van den Heuvel et al. 1993a). Thus, dsh appears to mediate the role of $w g$ in directing accumulation of Arm in wg-expressing and -flanking cells, as well as in maintenance of en expression in the posteriorly adjacent cells.

Wg-mediated induction across tissues of the midgut In addition to its role in epidermal development, $w g$ is also required for development of a region of the midgut (Immergluck et al. 1990; Reuter et al. 1990). In late wild-type embryos, a deep second midgut constriction forms just posterior to a broad band of labial (lab) expression in the endodermal layer (Fig. 2A). wg and $d s h$ embryos never form the second constriction (Fig. 2B,C). Although $w g$ is expressed in the visceral mesoderm at the site where the second midgut constriction will form (Reuter et al. 1990), it is required for correct expression of $l a b$ in the adjoining endoderm (Immergluck et al. 1990). Normally, lab expression forms a gradient of nuclear staining such that the strongest staining is in the cells adjacent to the constriction, with lower levels toward the anterior (Fig. 2D; Immergluck et al. 1990). In wg and $d s h$ mutants, this gradient is absent, with most cells in the $1 a b$ domain expressing lower levels of antigen (Fig. 2E,F; Immergluck et al. 1990|. Therefore, $d s h$ appears to mediate $w g$ function between cells in different germ layers.

\section{dsh and wg have similar phenotypes throughout development}

We investigated the relationship between $w g$ and $d s h$ during imaginal development to examine their phenotypic correlation in other developmental contexts. Hemizygous $d s h$ animals derived from heterozygous mothers usually die as late larvae or early pupae, but in the case of a hypomorphic lethal allele a few survive long enough to develop adult tissues. When these pharate pupae are dissected from their pupal cases, they exhibit defects primarily involving distal derivatives of the imaginal discs. Most notably, they lack antennal structures and have bulbous, truncated legs (Fig. 3B). The pupal phenotypes of $d s h$ are very similar to those of $w g$ pupal-lethal alleles, which also result in a lack of antennal structures and partial, malformed legs (Baker 1988b; Fig. 3C). Although the extent of defects in both mutants varies greatly from animal to animal, the sensitive tissues are affected in a similar way. The legs of $d s h$ pupae typically show a deletion of ventral markers, replaced with a duplication of dorsal pattern elements (Fig. 3D). These defects are also seen in legs of wg pupae (Peifer et al. 1991; Couso et al. 1993). wg mutants usually lack one or both wings, replaced by a duplicated notum (Baker 1988b; Fig. 3F); dsh animals occasionally show an identical defect $(\sim 20 \%$; Fig. 3E).

$\mathrm{dsh}$ and wg are required for ventral patterning of the leg Several experiments suggest that localized expres-

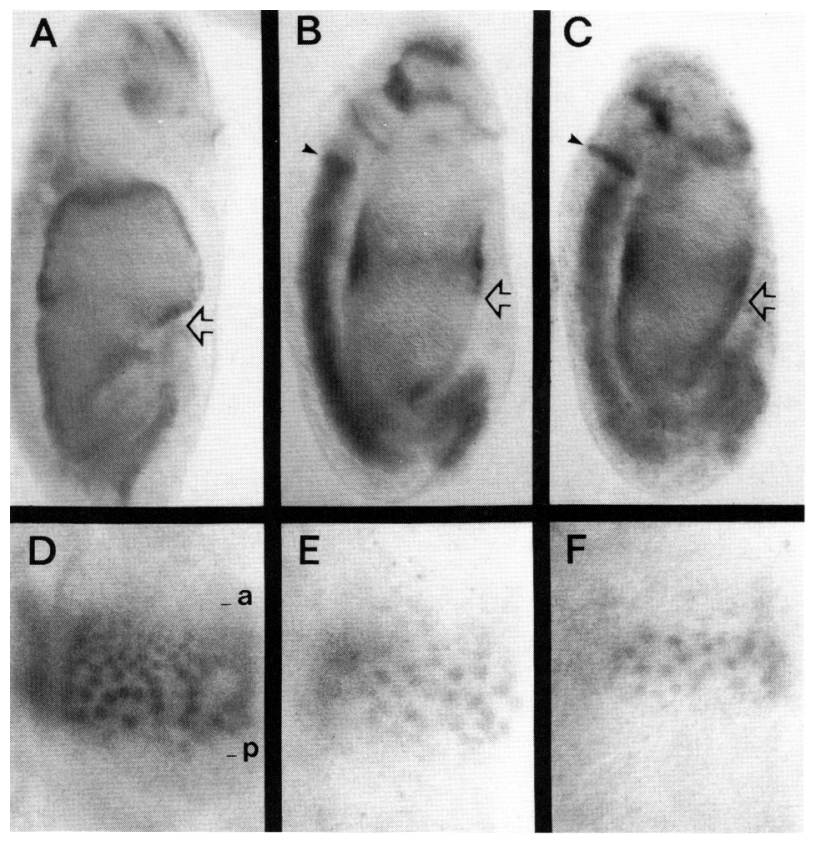

Figure 2. Midgut patterning is affected similarly in $d s h$ and $w g$ mutants. Whole-mount lateral, parasaggital views of embryos stained with anti-Lab with anterior up. (A) Wild-type embryo, stage 15 . The second midgut constriction (SMC) forms a sharp indentation in the midgut (open arrow), reaching its narrowest point just posterior to the domain of endodermal cells expressing Lab antigen (dark staining). The first and third constrictions become pronounced somewhat later. $(B) w g^{I N 67} / w g^{I N 67}$ embryo, stage 15 . The SMC is completely absent (open arrow), although Lab antigen still occurs in its normal domain in the midgut (dark staining). Ectopic Lab staining also occurs in the CNS (arrowhead). (C) $d s h^{v 26}$ embryo, stage 15. Lack of $d s h$ results in complete failure of the SMC (open arrow), despite Lab expression (dark staining). These embryos show identical defects to wg embryos, including the induction of ectopic Lab antigen in the CNS (arrowhead). (D) Wild-type embryo, stage 14. Lab antigen in the endodermal nuclei forms a graded pattern, with strongest staining at the posterior ( $\mathrm{p}$ ) of the domain where the SMC begins to invaginate. Toward the anterior (a) the nuclei look smaller and less heavily stained. $(E) \mathrm{wg}^{I N 67} / \mathrm{wg}^{I N 67}$ embryo, stage 14 . Lab staining is less intense overall and occurs in a nongraded manner. $(F) d s h^{\text {v26 }}$ embryo, stage 14. Lab staining is affected in the same way as in wg embryos.

sion of $w g$ in early larvae acts to organize ventral patterning in the leg disc (Peifer et al. 1991; Couso et al. 1993; Struhl and Basler 1993). We have investigated the requirement for $d s h$ in leg development by examining mosaic legs consisting of wild-type and $d s h$ mutant cells. As in the body as a whole, the frequency of $d s h$ clones in the leg is less than that of wild-type, control clones (Table 1; data not shown|. However, clones of cells lacking $d s h$ are recovered in even the most ventral bristle rows throughout the leg. Whereas dorsal and lateral $d s h$ clones seem to have no effect on development (Fig. 4A), ventral clones are almost always associated with supernumerary appendages arising from the ventral face of the leg (Fig. 4B,C,D). Control clones, in which the $d s h$ allele 


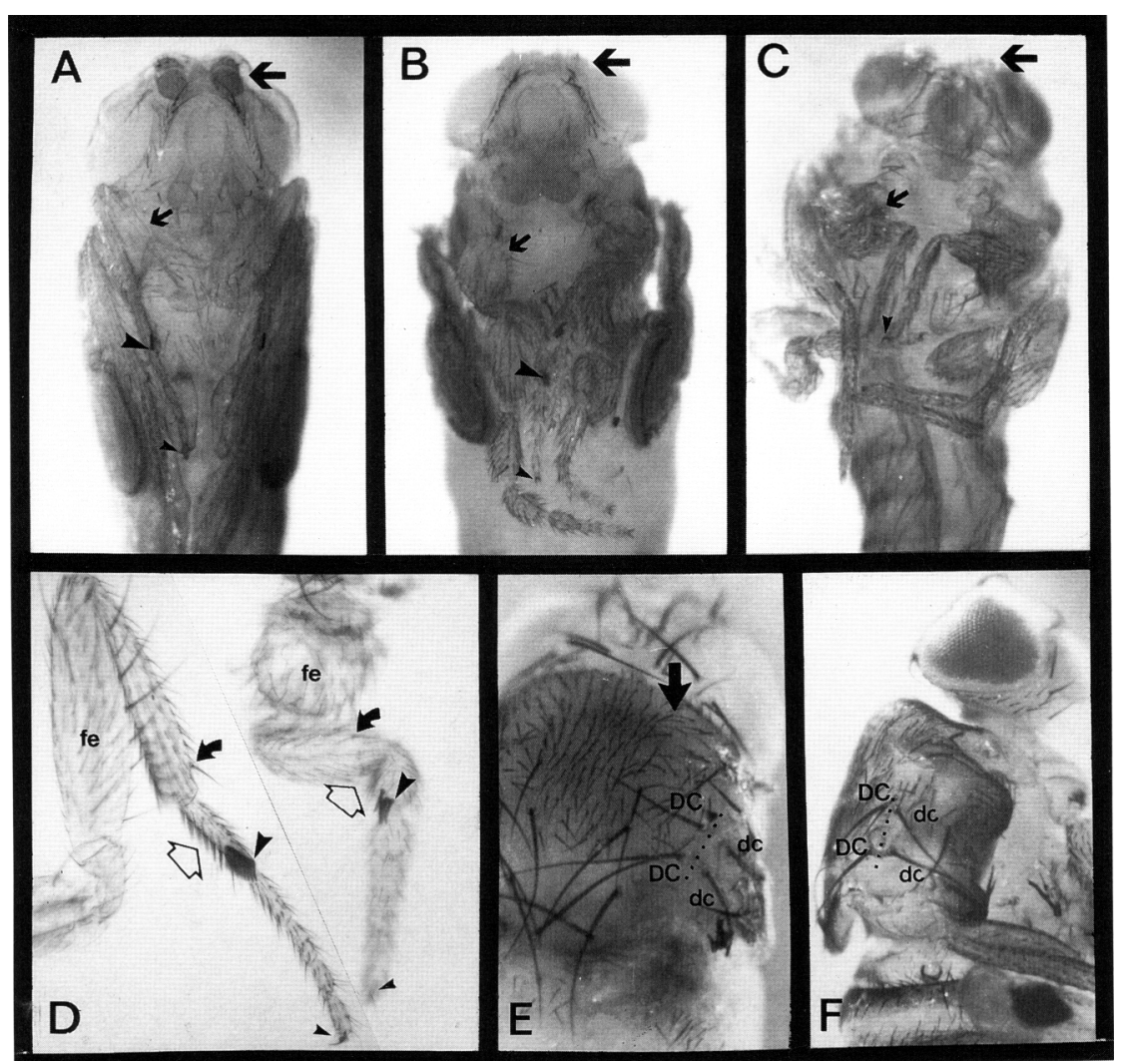

Figure 3. Phenotypes of $d s h$ in imaginal development. $(A)$ Wild-type pharate pupa, male (ventral aspect). Note the presence of antennae (large arrow) and the thin, tubular, and ordered appearance of the six legs. The femur of the first left leg is indicated (small arrow), and more distally the sex comb (large arrowhead) and claw (small arrowhead). (B) $d s h^{M 20} Y$ male pupa (ventral aspect). Note lack of antennal structures (large arrow) and truncated, malformed legs. The femur of the first left leg (small arrow) is short and bulbous. Sex comb (large arrowhead) and claw (small arrowhead) are present, indicating presence of dorsal pattern. The distal-most tarsal segments of legs are often lacking. $(C)$ wg pupa, female (ventral view, $\mathrm{wg}^{\mathrm{CX} 3} / \mathrm{wg}^{\mathrm{CX}}{ }^{4}$ ). The defects are similar to those of $d s h$, with a lack of antennae (large arrow) and incomplete, malformed legs; e.g., the femur of the left first leg is truncated and bulbous (small arrow). Claws often form (small arrowhead). Leg development is typically less affected in $w g$ than in $d s h$; wing development is usually affected more. (D) Prothoracic (first) male legs, wild-type (left) and $d s h$ (right). The femur of both legs is indicated ( $\mathrm{fe}$ ) - note that the $d s h$ femur lacks the long bristles characteristic of the wild-type ventral femur (right) and is much reduced in length. $d s h$ legs differentiate dorsal structures, such as the tibial subapical bristle (curved arrow) and the claw (small arrowhead). The dorsal edge of the sexcomb (large arrowhead) is also normal. Ventral structures are absent, such as the peg-like bristles in the tarsal segments (open arrow). (E) $d s h^{M 20} / Y$ pupa, dorsolateral view. The wing has been replaced by a duplication of the notum (right). The axis of duplication (dotted line) is flanked by the normal dorsocentral bristles (DC) and ectopic dorsocentral bristles (dc) in mirror-image symmetry. Note also the dishevelled alignment of the bristles on the thorax (arrow), which in wild type all point posteriorly. $(F) w^{C X 3} / w^{C X 4}$ pupa (lateral view). Axis of duplication is the same as in $E$.

was wildtype, were not associated with pattern irregularities in any compartment. The supernumerary appendages arising from $d s h$ clones can be composed of mutant (Fig. 4B) or wildtype cells (Fig. 4C). We have never observed any supernumerary dorsal appendages associated with clones. Therefore, both $d s h$ and wg are

Table 1. Mosaic analysis of dsh

\begin{tabular}{|c|c|c|c|c|c|c|c|}
\hline Cross & Genotype & Phase & Total & Mosaic & Autonomy & Nonautonomy & Ambiguous \\
\hline$F M 7 /$ svb $\times$ ring $-X / Y$ & svb/ring- $X$ & $\mathrm{E}$ & 62 & 9 & 6 & 0 & 3 \\
\hline GLC $s v b d s h \times$ ring- $X / Y$ & $s v b d$ sh/ring- $X$ & E & 161 & 22 & 16 & 1 & 5 \\
\hline$y w f / y w f \times X / Y$ & $y w f / X$ & A & 81 & $15^{\mathrm{a}}$ & 15 & 0 & 0 \\
\hline$F M 7 / y w d s h f \times X / Y$ & y $w d \operatorname{sh} f / X$ & A & 230 & 37 & 24 & 0 & $13^{b}$ \\
\hline
\end{tabular}

Numbers reflect results from single experiments; other experiments yielding similar results have been done in each case. Except when ring- $X$ instability was used to generate mosaics, progeny of crosses were irradiated in first to second instar to induce mitotic recombination. Females bearing germ-line clones (GLC) are homozygous for the genotype indicated. Numbers refer only to the progeny class of interest (genotype), scored for mosaicism as embryos (E) or adults (A). Animals showing marked and unmarked tissue (mosaic), were evaluated for autonomy or nonautonomousy of the $d s h$, shavenbaby $(s v b)$, yellow $(y)$, white $\{w\rangle$, or forked $(f)$ loci. Some mosaics were ambiguous: in embryos, because mosaic borders could not be seen due to folding, and in adults, because of cell death or lack of scorable phenotype. Data shown are for $d s h^{\mathrm{v} 26}$, but similar ratios were obtained with other lethal alleles. Clones indicated are the results of a single experiment, in which both genotypes were irradiated simultaneously.

${ }^{a}$ The frequency of clones wild type for $d s h$ was reproducibly higher than clones mutant for $d s h$ (lethal alleles), in this case $27 \%$ vs. $16 \%$. This is due at least in part to the absence of $d s h$ clones in distal-most portions of legs and antennae, in which $d s h$ is required for viability as judged from mutant phenotypes.

${ }^{\mathrm{b}}$ All $d s h$ clones were consistent with autonomy; however, large clones in the lower legs and antennae were usually associated with pattern regulation due to cell death or inappropriate fate (see text). In a separate analysis of clones in the leg, $0 / 47 \mathrm{control} y \mathrm{f}$ clones were associated with pattern defects. Among y $d s h^{v 26} f$ clones, $10 / 12$ ventral clones and $0 / 14$ dorsal clones were associated with pattern abnormalities, such as missing bristles and outgrowths from the plane of the leg. 
Figure 4. Clonal analysis of $d s h$ in imaginal development. Genetically marked clones of $d s h$ mutant cells in heterozygous females. $|A|$ y $d s h^{\text {v26 }} f^{36 a}$ clone, first leg femur (lateral view). The clone of mutant cells (within broken line) is marked by yellow and forked, resulting in bent bristles of light pigmentation (small arrowhead). In lateral or dorsal (D) locations, clones of $d s h$ mutant cells (large arrowhead) do not result in any abnormal patterning. A dorsal pattern element is indicated by the open triangle. The ventral $(\mathrm{V})$ face is indicated. $(B)$ y $d s h^{v 26} f^{36 a}$ clone, first leg femur (lateral view). The ventral clone (large arrowhead; below broken line) of $d s h$ mutant cells in the leg is shown, occurring on a duplicated appendage. The cells on the supernumerary tissue secrete only mutant bristles (small arrowhead). $(\Delta, \Delta)$ Dorsal (D) and ventral (V) markers, respectively. $(C)$ y $d s h^{\text {v26 }} f^{36 a}$ clone, second leg tibia (lateral view). Triplication of tarsal segments resulting from clone (within broken line) at distal end of tibia. The axis of mutant tissue is marked by bristle markers (small arrowhead), forming a truncated appendage (large arrowhead). A second ectopic axis is indicated by the arrow and appears to consist entirely of wild-type cells with two ventral surfaces, indicated by the thick, peg-like bristles on either side. The normal basitarsus extends to the left. The ventral (V) face is characterized by thick, peg-like bristles. ( $\mathbf{\Delta})$ Indicative ventral pattern elements; $(\Delta)$ dorsal (D). (D) y $d s h^{v 26} f^{36 a}$ clone, third leg basitarsus [ventral (V) view]. A supernumerary appendage grows out of the ventral face, associated with a large ventral and ventrolateral $d s h$ mutant clone (large arrowhead), as indicated by the distribution of marked bristles (small arrowhead). The clone and duplication (below broken

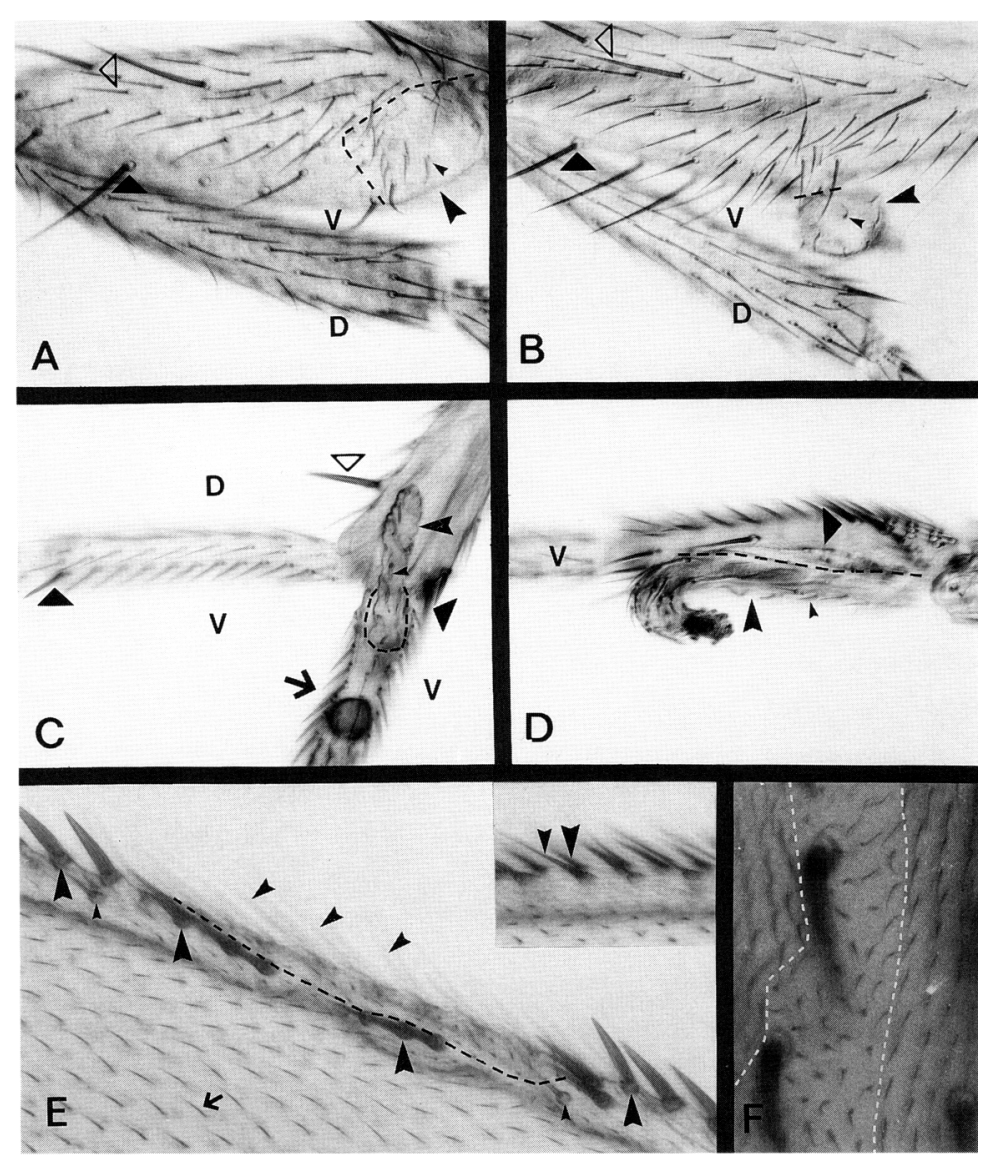
line) lie immediately adjacent to the ventral-most cells, which secrete large, thick bristles $(\mathbf{\Delta})$. (E) y dsh ${ }^{\mathrm{v} 26} f^{36 a}$ clone, anterior wing margin (dorsal view). The mutant cells are revealed by their marked hairs (above broken line). Wild-type cells, with straight hairs (arrow), do not occur between the ventral (medium arrowheads) and medial (large arrowheads) bristles. These bristles normally abut each other, with no intervening hair cells, as seen in the more ventral view of a wild-type wing (inset). This clone has displaced the medial bristles to the level of the dorsal bristle row (small arrowheads). (F) y $d s h^{v 26} f^{36 a}$ clone (dorsal thorax, anterior up). The $d s h$ lesion disrupts the polarity of hairs, each of which is the product of a single cell. The f $f^{36 a}$ mutation makes hairs slightly thin and bow-shaped but does not alter their polarity. The hairs in this clone, only $4-6$ cells wide, show the $d s h$ phenotype, in that their polarity is chaotic. Adjacent wild-type hairs are unaffected. The mutant region lies between the broken lines. The large structures are microchaetae. [The patterning defects shown were observed regardless of whether mutant clones were induced following X-ray irradiation or by sitespecific recombination.]

required in the leg by ventral cells, among which it is necessary for patterning but not viability.

dsh and wg function in patterning of the wing margin In the wing discs of late larvae, $\mathrm{wg}$ is expressed in a narrow strip of cells that form the wing margin (Baker 1988b; Phillips and Whittle 1993). A predifferentiation property of these cells is that they stop proliferating sooner than other cells in the disc, forming a "zone of non-cell proliferation" (O'Brochta and Bryant 1985). Experiments involving a temperature-sensitive allele of $w g$ reveal that $w g$ is required to make these cells quiescent (Phillips and Whittle 1993). We tested whether null alleles of $d s h$ might result in wing margin defects by inducing clones of mutant cells during larval stages. When clones of cells lacking $d s h$ occur at the margin of otherwise wild-type wings, the normal distribution of pattern elements at the wing margin is altered in a manner sug- gestive of excess cell proliferation. For example, the anterior wing margin is decorated with a triple row of bristles (Hartenstein and Posakony 1989), with one or no hair-secreting cells occurring between the ventral and medial rows (Fig. 4E, inset). dsh clones in this region result in supernumerary cells at the margin. The extra cells are mutant, as indicated by a genetically linked hair morphology marker, whereas the surrounding bristle and hair cells are wild type (Fig. 4E). These experiments suggest that, like $w g, d s h$ is required for normal proliferation and patterning of cells at the wing margin.

\section{dsh is cell autonomous}

The experiments described show that $d s h$ is involved in $w g$-mediated patterning in multiple tissues throughout development. In each instance we studied, the defects of 
A

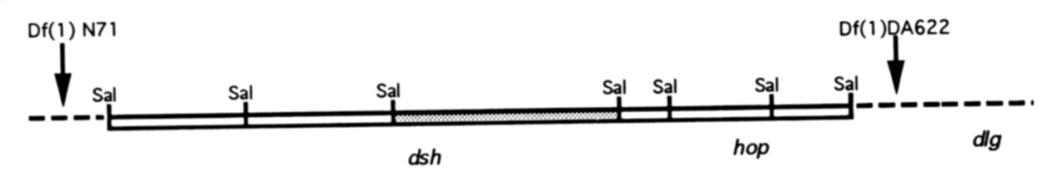

B
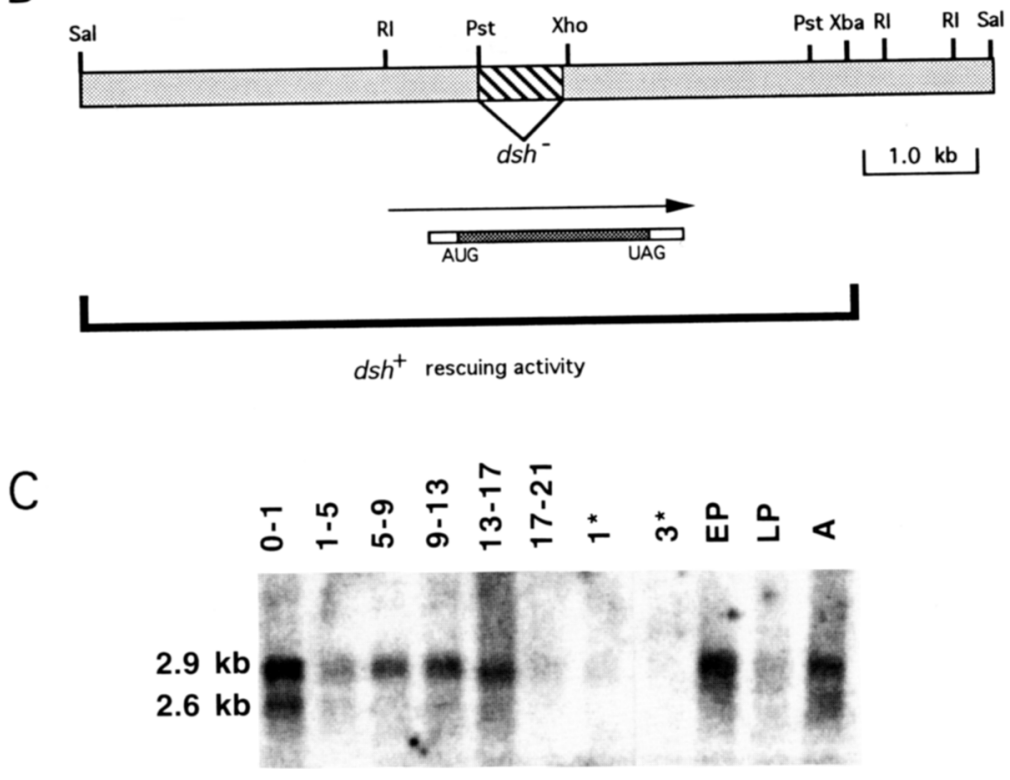

D

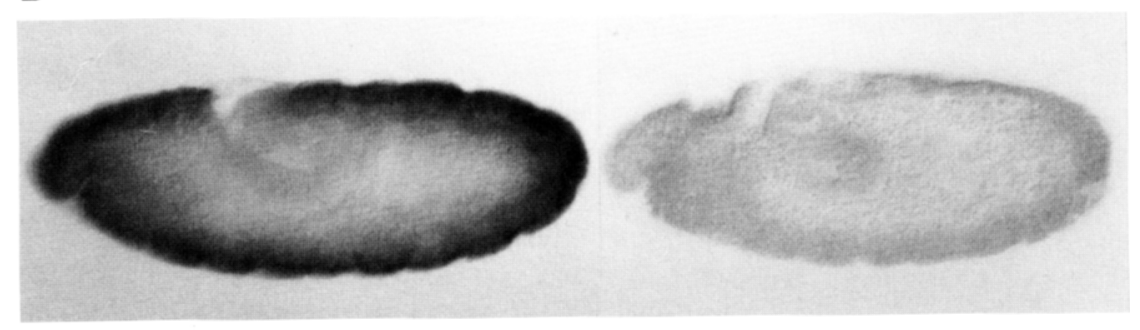

Figure 5. Molecular cloning and expression of $d s h$. (A) Genetic map of the $d s h$ region. $d s h$ maps to the $10 \mathrm{~B} 6$ region of polytene chromosomes between the deficiency breakpoints of $D f(1) N 71$ and Df(1)DA622, just distal to hopscotch (Perrimon and Mahowald 1987). We used a series of Sall fragments extending distally from hop to probe genomic DNAs of $d s h$ alleles for rearrangements. $(B)$ Structure of the $d s h$ locus. A 7.9-kb Sall fragment detected a change in $d s h^{v 26}$, which proved to be a deletion of $\sim 600 \mathrm{bp}$ (hatched box). A 0.65-kb PstI-XhoI fragment spanning the deletion was used to probe developmental Northern blots and to screen an embryonic cDNA library. The extents of the transcript detected, the corresponding largest cDNA, and the ORF within it are indicated. On the basis of this mapping data, we designed a P-element rescue construct that contained a $6.7-\mathrm{kb}$ SalI-XbaI fragment as shown below. All lines tested rescued all $d s h$ phenotypes. $(C)$ Developmental profile of $d s h$ expression. The blot is loaded with poly $\left(\mathrm{A}^{+}\right)$-selected RNA derived from animals of the indicated ages (in hr) and probed with the $d s h$ cDNA (dc2.6). The messages detected are exactly those detected by the $0.65-\mathrm{kb}$ genomic fragment used to screen the cDNA library. A 2.9 -kb transcript is expressed throughout development, falling to low levels during larval stages. A $2.6-\mathrm{kb}$ transcript is strictly maternal. Time points: $\left(1^{*}\right)$ first instar; $\left(3^{*}\right)$ third instar; (EP) early pupae; (LP) late pupae; (A) adults-both males and females. All lanes are approximately equally loaded except $13-17 \mathrm{hr}$, which is overloaded by about twofold. $(D)$ Wholemount in situ hybridizations with $d s h$ (left) and vector (right) probes, stage $11 \mathrm{em}$ bryos. The $d s h$ probe was a 650 -bp PstI$X$ hol fragment, which hybridizes to a transcript uniformly distributed in the embryo, at highest levels in the epidermis. The control probe was a fragment derived from the vector pBSK, prepared and hybridized in parallel. $d s h$ are consistent with the interpretation that $d s h \mathrm{mu}$ tant cells are unable to respond to the cell fate signals specified by wg and thus adopt an inappropriate fate. If so, $d s h$ would be expected to behave cell-autonomously; that is, a given cell in a responsive tissue would require $d s h$ to achieve its normal fate, regardless of its neighbors. We tested the cellular requirement for $d s h$ via mosaic analysis.

To determine the cellular requirement for $d s h$ in embryos we examined the phenotype of large patches of mutant tissue in otherwise wild-type embryos. Such mosaics are comprised of both denticle belts in wild-type pattern and a patch of cuticle covered with denticles in disorganized array (Table 1 ; Fig. 1E), showing that the mutant tissue has not been rescued. For comparison, we made similar chimeric embryos for arm /data not shown), using an allele with the same developmental genetics and phenotype as $d s h$ and that functions cell autonomously in embryos (Klingensmith et al. 1989). We observed the same kind of mosaics in both cases, suggesting that $d s h$ is also cell autonomous. However, the clone boundary among denticle-secreting cells cannot be determined in these embryos. To make this determination, we marked mutant cells with the cell-autonomous cuticle marker shavenbaby (svb) (Table 1; Fig. 1D,F), which decreases the size and number of denticles /Ger- 
gen and Wieschaus 1986). Examination of $s v b$, dsh mosaics reveals that genotypically mutant tissue is phenotypically mutant as well (Table 1 ), in that $s v b$ denticles always occur in the pattern seen in nonmosaic $s v b, d s h$ mutants (Fig. 1G). Although not scorable at single-cell resolution, these mosaics strongly suggest that $d s h$ is cell autonomous in its embryonic function.

To study the cellular requirement for $d s h$ in imaginal development, we generated mosaics bearing small patches of $d s h$ mutant tissue (Table 1). As described above, $d s h$ pupae exhibit defects similar to those of $w g$; in addition, they have a tissue polarity defect in which the polarity of hairs and bristles is chaotic, seen most clearly on the dorsal thorax. Because a given hair is the product of a single epidermal cell (Poodry 1980; Mitchell et al. 1983), this feature can be used to determine $d s h$ phenotype at the level of individual cells. Thoracic $d s h$ clones show the tissue polarity defect, but adjacent wildtype cells have hairs of wild-type polarity (Fig. 4F). This holds true whether the clone spans hundreds of cells or a few cells, revealing that $d s h$ acts cell autonomously in imaginal patterning.

The cells involved in abnormal pattern in the $d s h$ clones in the wing margin and leg disc sometimes include wild-type cells, as described above. However, in both cases, the cause of the abnormality appears to be a cell-autonomous defect in the cells lacking $d s h$. In the wing margin, only $d s h$ cells occur ectopically, resulting in a displacement of the bristle cells normally residing there. In the leg, pattern regulation seems to result from a failure of ventral $d s h$ cells to behave in a manner consistent with their location (see Discussion).

\section{Molecular identification of dsh}

The most distal genomic phage clone from the discslarge (dlg; Woods and Bryant 1989, 1991; Fig. 5A) region provided a starting point for a chromosomal walk to clone the genomic DNA encoding hopscotch and dsh (Binari and Perrimon 1994). Restriction digests of the various alleles of $d s h$ were probed with restriction fragments of genomic DNA extending from the hop region toward the distal N71 breakpoint (Fig. 5A). One allele, $d s h^{\text {v26, }}$, carries a deletion of $\sim 600 \mathrm{bp}$ relative to its parental chromosome (Fig. 5B; data not shown). A probe corresponding to the deleted region hybridizes to messages of 2.9 and $2.6 \mathrm{~kb}$ among RNA derived from very early embryos, before transcription of the zygotic genome. The larger transcript is detected also in RNA from later stages (Fig. 5C). Mapping of these transcripts allowed design of a P-element rescue construct (Fig. 5B). Each of the five independently derived transgenic lines tested rescued all $d s h$ phenotypes to full viability and normal pattern.

A genomic restriction fragment encompassing the region deleted in $d s h^{v 26}$ was used to screen an embryonic cDNA library (Materials and methods). On Northern blots, the cDNA inserts hybridized to the same transcripts detected by the genomic probe (Fig. 5C). Thus, the two transcripts encoded by the deleted region and encompassed by the rescuing construct are related. Although these are the only transcripts encoded entirely by the genomic fragment that rescues $d s h$, other transcripts hybridize to the outer ends of the fragment /data not shown). To demonstrate conclusively that $d s h$ functions are encoded by the cDNAs isolated and not by truncated products from one of the other transcripts, we cloned the largest cDNA into a heat-inducible P-element expression vector (Materials and methods). Basal levels of expression from two separate transformants were sufficient to rescue all embryonic $d s h$ phenotypes.

Whole-mount in situ hybridization experiments revealed that $d s h$ message is distributed uniformly throughout the embryo through germ-band shortening (Fig. 5D). This is consistent with the observation that ubiquitous, low level expression of $d s h$ permits completely wild-type embryonic development.

Sequence analysis of dsh and structural implications Sequencing of the rescuing cDNA revealed that it contains a single significant open reading frame (ORF; Fig. 6). The deduced amino acid sequence indicates a 623-amino-acid protein of $70 \mathrm{kD}$. This cDNA encodes a protein of $\sim 70 \mathrm{kD}$ when subjected to in vitro transcription and translation (J. Klingensmith, R. Nusse, and N. Perrimon, unpubl.).

The sequence implies several structural features of the protein (Fig. 6). A tract composed largely of glutamines corresponds to an opa repeat, as found in many Drosophila proteins (Wharton et al. 1985). Several regions conform to the criteria for PEST sequences, which are correlated with rapid turnover of proteins (Rogers et al. 1986). Three stretches of hydrophobic residues are sufficiently long to raise the issue of whether they span the membrane. However, their predicted structure and averaged hydrophobicity suggest that they probably do not (Kyte and Doolittle 1982; Rao and Argos 1986). In microsomal incorporation assays of the in vitro translation product, the Dsh protein does not appear to enter the secretory pathway (F. van Leeuwen and J. Klingensmith, unpubl.).

dsh encodes a novel but conserved protein with limited homologies to junctional proteins Searches of several data bases failed to find any reported sequence with extensive homology to the dsh ORF. However, genes highly homologous to $d s h$ have been cloned in several vertebrates, including mouse (D. Sussman, J. Klingensmith, P. Salinas, R. Nusse, and N. Perrimon, in prep.), human (D. Beier, pers. comm.), and frog (S. Sokol, pers. comm.|. Predicted structures of these homologous genes also fail to indicate what molecular function they might serve.

The only significant similarities detected in data base searches were to the Drosophila junctional protein Discs-large (Dlg) and its relatives. The block of homology is in the middle of the ORF, in the center of a long region of very high homology among all known Dsh cognates. The conserved motif is also found in postsynaptic density protein 95 (PSD-95) and erythrocyte membrane protein $\mathrm{p} 55$, which have one or more repeats of this domain, an SH3 domain, and a guanylate kinase domain 
1 ATTCCGCTAGAGCGACCAGGGGGAGAAAAGGCAAAATCGAGTGAATTTTGTTTGTTGTAT 121 CACCTCCCCACCGCATCCATCGCATTTCGTTTTGATCGCGTTTTATCGCGTCGAGGAGTT

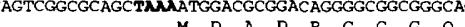
$\begin{array}{llllllll}M & D & A & D & R & G & G & G\end{array}$

241 GAGACGAAGGTGATATACCACATCGACGATGAGACGACGCCGTATCTGGTGAAGATCCCC $\begin{array}{llllllllllll}E & T & K & V & I & Y & H & I & D & D & E & T\end{array}$ $\begin{array}{llllllllllllllllllll}I & P & S & A & Q & V & T & L & R & D & F & K & L & V & L & N & K & Q & N & N \\ I & N & \end{array}$ $\begin{array}{llllllllllllllllllll}N & Y & K & Y & F & F & K & S & M & D & A & D & F & G & V & V & K & E & E & I\end{array}$ GCCGACGACTCCACCATACTGCCCTGCTTCAATGGGCGAGTGGTGTCCTGGCTGGTCTC

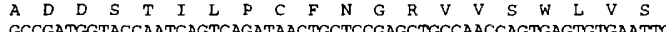
GCCGATGGTACCAATCAGTCAGATAACTGCTCCGAGCTGCCAACCAGTGAGTGTGAATTO

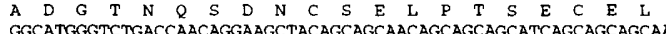

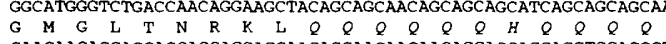
CAACAACAGCAGCAGCAGCACCAGCAACAGCAACAACAACAGCAGCAGCAGGTGCAGCC

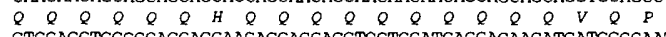
GTCCAGCTGGCGCAGCAGCAACAGCAGCAGGTGCTCCATCACCAGAAGATGATGGGCAAT

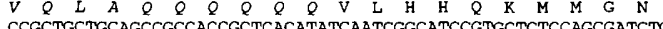
CCGCTGCAGCGCCACCGCTCACATATCAATCGGCATCCGTGCTCTCCAGCGATCTO Th Y Q S

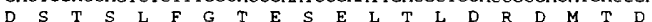
$Y \quad S \quad S \quad V \quad Q \quad R \quad L \quad Q \quad V \quad R \quad K \quad K \quad P \quad Q \quad R \quad R \quad K \quad K \quad R$

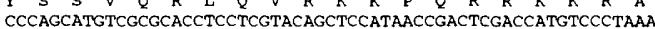

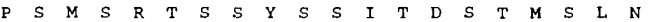
$\begin{array}{llllllllllllllllllllll}I & I & T & V & S & I & N & M & E & A & V & N & F & L & G & I & S & I & V & G\end{array}$ CAATCGAATCGCGGCGGCGACGGCGGCATCTACGTGGGCAGCATCATGAAAGGCGGCGCA

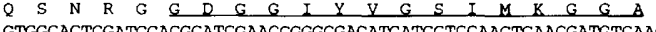
GTGGCACTCGATGGACGCATCGAACCGGGCGACATGATCCTCCAAGTGAACGATGTCAAC

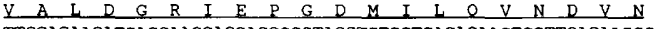
TTCGAGAACATGACCAACGACGAGGCGGTACGTGTGCTGAGAGAAGTCGTTCAGAAGCC $\begin{array}{llllllllllllllllllll}F & E & N & M & T & N & D & E & A & V & R & V & L & R & E & V & V & Q & K & P\end{array}$ 1 GGACCCATCAAGCTGGTGGTGGCCAAGTGCTGGGACCCAAATCCCAAGGGCTACTTCACC $\begin{array}{lllllllllllllllllllll}G & P & I & K & L & V & V & A & K & C & W & D & P & N & P & K & G & Y & F & T\end{array}$ ATTCCGCGCACGGAGCCGGTGCGACCCATCGATCCCGGTGCTTGGGTGGCGCACACTCA

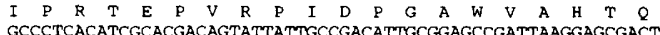

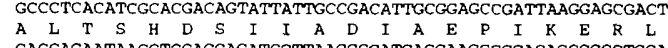
GACCAGAATAACCTCGAGGAGATCGTTAAGCGATGACGAACCGGACAGCGGCCTGGAG
$D$ 1 ATCAGGGATCGCATGTGGCTAAAGATAACGATTCCCAATGCATTTATCGGCGCCGATGCC $\begin{array}{lllllllllllllllllllll}I & R & D & R & M & W & L & K & I & T & I & P & N & A & F & I & G & A & D & A\end{array}$ G $V$. $\mathrm{V}$ T G

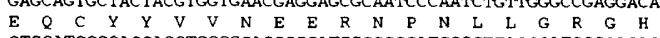
CTGCATCCGCACCAGCTGCCGCACGGGCATGGCGGCCATGCGCTTAGCCATGCGGACACC

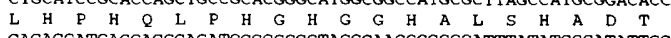
GAGAGCATCACCAGCGACATCGGGCCGCTACCGAACCCGCCCATTTATATGCCATATTC

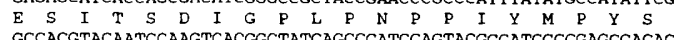

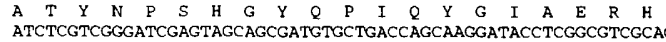

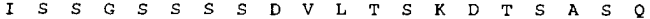
AGCGACATCACCTCGGTGATCCATCAGGCCAACCAGCTGACCATCGCCGCTCATGGCTC

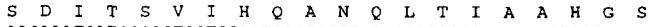
AACAAATCATCCGGCTCCTCCAATCGGGGCGGCGGCGGAGGCGGTGGCGGTGGCGGCAAC

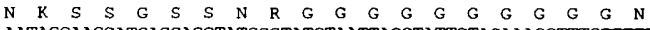
AATACCAACGATCAGGACGTATCCGTATCTAATTACGTATTGTAGAAACCTTTCTTTTTG N $T$ T N CAATGTGTTTTTAATTAATTAAATTAAATATGTACCGGATTATTCTTTTTTATATACGA TATACAAGCAGCAACAGCAACCACAATATAATAATTATAATTATAATAATAATAATAATA ATAATTATAATAATAATAATAATACTTATGTATATGTATGGTATGTGTAAGTCATAGAAA AGAGCIARCACCAGCGCACGAGTCAGGATCAGCGAGGCTCGGAGCAGCAGAGATCAGCA

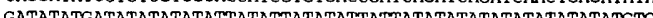

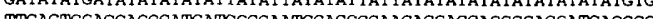
TTGAGTGCAGGACGGATGATGCGGAATGGAGCGGAAGAGCAGGACGGCAGCATGACGGCC GAGAATGATTTTGMATMAAGTTCTAAGA

Figure 6. The deduced Dsh amino acid sequence. The nucleotide sequence of the $d s h$ cDNA dc2.6 is shown, along with its only significant ORF. At the 3 ' end are three potential polyadenylation signals (bold), followed by a string of 14 As (underlined). At the $5^{\prime}$ end, the first methionine of the ORF (and of the cDNA) is preceded by a good match (bold) to the Drosophila translational start site consensus (C/A A A C/A; Cavener 1987). The ORF encodes a putative protein of 623 residues. An Opa repeat extends from residues 118 to 159 (italics). Several stretches conform to the criteria for PEST sequences. Two long runs of hydrophobic residues occur near the middle of the protein. Within this region is a domain of homology to Dlg and its relatives (underlined), extending from residues $274-308$. There are numerous potential post-translational modification sites, including those for certain serine-threonine kinases, for aminolinked glycosylation, and for myristilation. One region of basic residues $(224-228)$ is similar to that of nuclear localization signals.
(Bryant and Woods 1992; Cho et al. 1992). Dsh and its homologs have neither of these other domains. A less conserved version of this domain is present in the gene encoding nitric oxide synthase (bNOS), which is otherwise unrelated to the other genes (Bredt et al. 1991). The alignment of these sequences is shown in figure 7 with a consensus sequence.

\section{Discussion}

dsh functions in the response of cells to the wg signal

Throughout development, lack of $d s h$ function results in defects similar to those seen in $w g$ mutants. Several lines of evidence strongly support the hypothesis that the role of $d s h$ in wg signaling is to allow target cells to respond and that $d s h$ therefore functions in the reception or interpretation of the $w g$ signal. First, $d s h$ functions cell autonomously; a cell devoid of $d s h$ function has the mutant fate. Because wg function is nonautonomous (Morata and Lawrence 1977; Babu and Bhat 1986; Baker 1988a; Struhl and Basler 1993), genes that are involved in signal production would also be expected to be nonautonomous, whereas genes involved in responding to the signal are expected to be cell autonomous. The $z w 3$ gene has been shown genetically to function downstream of $w g$ in regulating en expression (Siegfried et al. 1992) and is cell autonomous (Perrimon and Smouse 1989; Simpson et al. 1988).

We have presented several experiments demonstrating or supporting the cell-autonomy of $d s h$. The best demonstration is the tissue polarity phenotype of mutant $d s h$ clones in the adult thorax. Even very small clones of only a few cells have abnormal polarity, indicating that $d s h$ is cell autonomous. However, because this phenotype may be unrelated to wg function, we sought independent evidence that $d s h$ functions cell autonomously in wg-dependent processes. To study the requirement for $d s h$ in embryonic segmentation, we made large patches of mutant cells and studied their denticle pattern. Mutant cells exhibit the mutant pattern, and wild-type cells contribute to wild-type pattern. $d s h$ cells appear to behave in a cell-autonomous manner in wg-mediated leg and wing development as well, but the defects of mutant clones most likely result in local pattern regulation (see below).

More data consistent with the idea that $d s h$ functions in the target cells of $\mathrm{wg}$ come from immunohistochemical experiments. $\mathrm{Wg}$ protein is expressed in $d s h \mathrm{em}$ bryos in an entirely normal pattern until after En has decayed. Under light microscopy, $d s h$ mutants have no effect on distribution of $\mathrm{Wg}$ protein prior to its deterioration. The temporal and spatial pattern of En decay is identical in $d s h$ and $w g$ embryos. The level or distribution of Arm protein is also regulated by wg and $d s h$ (Riggleman et al. 1990), and it in turn is necessary for the effects of $w g$ on en expression and cuticle patterning (Klingensmith et al. 1989; Noordermeer et al. 1994). dsh is upstream of $z w 3$, whereas arm is downstream (Siegfried et al. 1994). These genes are all cell autonomous, consistent with their apparent function in response to 
Figure 7. Homology to the "undefined domain" of DIg. Alignment of several sequences displaying homology to the undefined domain of $\mathrm{Dlg}$, listed in order of decreasing similarity to Dsh, as indicated (right). The location of the first residue indicated for each sequence within its ORF is indicated at left. The mouse dishevelled-1 homolog (Dvl) is virtually identical to Dsh in this region. For Dlg and its rat homologs, PSD-95, and erythrocyte major palmitylated protein p55, only the most homologous of the three repeats of this domain in each sequence are shown. The domain is also found in bNOS. This region has been refered to as the "GLGF" domain by Cho et al. (1992), which occurs several amino acids prior to the region shown; however, the GLGF residues are not conserved in the Dsh, Dvl, or p55 proteins. A consensus sequence of residues conserved in five or more (uppercase letters) or a majority (lowercase) of the domains is indicated below. In some cases, either of two residues occurs in a given position. We indicate both in the consensus.

the Wg signal. Moreover, all three are expressed uniformly in the embryonic epidermis (Riggleman et al. 1990; Siegfried et al. 1990), as expected based on the ability of all such cells to respond to $\mathrm{Wg}$ (Noordermeer et al. 1992).

\section{wg and dsh in imaginal patterning}

The phenotypes of pupal lethality of $w g$ and $d s h$ hypomorphic alleles are very similar, in that the distal derivatives of most discs fail to form or are truncated. Analysis of the consequences of $w g$ under- or overproduction in the leg disc suggests that wg acts to promote ventral cell fates during early larval development of the leg discs (Couso et al. 1993; Struhl and Basler 1993). Clones of cells lacking either arm (Peifer et al. 1991) or $d s h$ result in abnormal ventral patterning in the leg. This suggests that the pathway mediating $w g$ signaling in the embryonic epidermis may also function in the imaginal epidermis. However, unlike $a r m, d s h$ is not required for cell viability in the ventral compartment of leg discs; rather, $d s h$ appears to be required specifically for normal ventral patterning.

Whereas dorsal $d s h$ clones in the proximal leg have no adverse effect on patterning, ventral clones are invariably associated with pattern irregularities. Typically, supernumerary appendages consisting of mutant or wildtype cells arise from the ventral face of the leg. These outgrowths are similar to those that arise out of dorsal aspects of legs in association with dorsal clones of cells overexpressing $w g$, whereas ventral clones of $w g$ overexpression are inconsequential (Struhl and Basler 1993). These workers noted that supernumerary appendages of this nature result from grafting experiments in which dorsal and ventral leg tissues are directly juxtaposed (e.g., French 1978). They reasoned that if $w g$ induces ventral fates, cells overexpressing $w g$ in dorsal tissue would cause such a juxtaposition. Similarly, if $d s h$ is required by cells to respond to the $\mathrm{Wg}$ signal, thereby becoming ventralized, then clones of cells lacking $d s h$ in the ventral compartment would juxtapose wild-type, ventral and mutant, nonventral cells. The predicted consequence is observed: ventral supernumerary appendages.
We have presented several results indicating that $d s h$ functions in a cell-autonomous manner, yet these ventral outgrowths often involve wildtype cells. Similarly, although arm functions cell autonomously (Wieschaus and Riggleman 1987; Klingensmith et al. 1989|, arm clones can also give rise to nonautonomous patterning defects in the leg (Peifer et al. 1991). One possibility is that these genes do function in an anomalous, nonautonomous manner in this particular context. However, we suspect that the apparent nonautonomy is a secondary consequence of cell-autonomous defects followed by pattern regulation (French et al. 1976). In the case of $d s h$, this would be a consequence of inappropriate juxtapositions as described above, whereas in arm mosaics pattern regulation would occur among the cells remaining after death of the mutant arm cells (Peifer et al. 1991).

In clones mutant for a null allele of $d s h$ induced through mid-third instar, we observe a displacement or absence of bristles normally at the margin, replaced by mutant cells that do not make bristles, sometimes straddling the dorsal-ventral border. Examination of the genotype of these cells, using linked cuticular markers, shows that the cells between the normal margin elements and the displaced elements are always mutant while the displaced bristles are always wild type. The data suggest that these $d s h$ clones result in a cell-autonomous overproliferation of non-neural cells along the wing margin. If $\mathrm{Wg}$ is required as a signal to slow division at the wing margin (Phillips and Whittle 1993), cells lacking Dsh may be unable to respond.

\section{Dsh represents a novel signal transduction molecule}

We have presented evidence that $d s h$ functions in the reception or interpretation of the Wg signal. Dsh may feed into a kinase-mediated signal transduction pathway to the nucleus since it functions upstream of $z w 3$, a serine-threonine kinase (Siegfried et al. 1992, 1994) in Wg signaling. However, how dsh might act to transduce the Wg signal is not revealed or suggested by its sequence. Because Dsh doesn't appear to be an integral membrane protein, it seems unlikely that it encodes a transmembrane receptor. 
The only detected homologies to Dsh are found in junction proteins. Dsh has a domain homologous to a repeated sequence found in Dlg and PSD95. Dlg encodes a Drosophila tumor suppressor gene that localizes to septate junctions and is thought to be involved in transduction of proliferation signals (Woods and Bryant 1991). PSD-95 is a major component of postsynaptic densities, which are junctions involved in the reception and transduction of synaptic stimuli (Cho et al. 1992). A more divergent homolog of these genes is erythrocyte membrane protein $\mathrm{p} 55$, which is also peripherally associated with the plasma membrane (Ruff et al. 1991; Bryant and Woods 1992). The conserved sequence homologous to Dsh in these genes, termed the "undefined domain" by Bryant and Woods (1992), occurs in three repeats in the amino-terminal half of Dlg and relatives. Their function is unknown, but in Dlg it is speculated that this general part of the protein may associate with junctions (Woods and Bryant 1991). The only other reported sequence with this motif is bNOS (Bredt et al. 1991), which is otherwise unrelated to either Dsh or Dlg. Interestingly, some bNOS is associated with neuronal membranes (Bredt et al. 1990). Because none of these proteins has other features suggesting membrane localization, it is tempting to speculate that the undefined domain motif promotes peripheral association with the plasma membrane and that Dsh might be found there.

The results presented here suggest that Dsh is very specific to Wg-mediated patterning events until late in imaginal development and that it is involved in the specific response of cells to the cell fate instructions dictated by $w g$ in many or all cases. In contrast, $z w 3$ is involved in many other patterning mechanisms. For example, $z w 3$ is involved in lateral inhibition in the wing (Blair 1992) and also appears to function downstream of Notch, a cell-autonomous receptor-like protein (Heitzler and Simpson 1991; Ruel et al. 1993). These considerations suggest to us that Dsh renders a more general signal transduction pathway specific for $\mathrm{Wg}$ signaling. Possibly Dsh is part of a receptor complex specific to the Wg signal, with binding of the ligand activating a more general transduction pathway. We have no evidence that Dsh is not part of a receptor complex, although the structural data we have presented suggest it is not a receptor in itself. If Dsh is downstream of the actual receptor, then its specificity suggests that the receptor also should be highly specific to the $\mathrm{Wg}$ signal. Alternatively, it is possible that Dsh gives specificity to a general signal reception-transduction pathway at the intracellular level. Wg signal would then be bound by a general receptor, and Dsh would channel transduction of this particular stimulus through the pathway mediated by Zw3.

\section{Materials and methods}

Fly stocks

The origins of $d s h^{v 26}, d s h^{M 20}, d s h^{V A 153}$, and $d s h^{1}$ are described in Perrimon and Mahowald (1987). Isogenic control chromosomes for v26 (v24 and v145) are reported in Geer et al. (1983). ${ }{ }^{I N 67}$ behaves as a null allele but makes a protein that appears not to be secreted in transfected cells or in embryos (van den Heuvel et al. 1993b). The markers yellow $\left(y^{1}\right)$, white $\left(w^{1}\right)$ and forked $\left(f^{36 a}\right)$ are described by Lindsley and Grell (1968). Embryonic cuticles were marked with $s v b^{Y P 17 b}$ (Gergen and Wieschaus 1986). Germ-line clones were produced using either ovo ${ }^{D 1}$ or $O V O^{D 1}, F R T^{101}$; FLP $P^{38} / F L P^{38}$ (Chou and Perrimon 1992) as described previously. The ring- $X$ chromosome (maintained with In(1)dl-49, y w lz/ $\mathrm{Yy}^{+}$) was obtained from J. Hall (Brandeis University, Waltham, MA). Embryos were mounted for cuticle inspection as described by Wieschaus and Nüsslein-Volhard (1986). Wild-type embryos were Canton-S or Oregon-R (Ore-R). All embryos and flies were grown at $25^{\circ} \mathrm{C}$.

\section{Whole-mount embryo stainings and genotype identification}

Embryos aged 5-20 hr for anti-Lab stainings or 2-8 hr for other stainings were prepared as described in van den Heuvel et al. (1989). Immunostainings with polyclonal antibodies against Wg (van den Heuvel et al. 1989) and Lab (T. Kaufmann, Indiana University, Bloomington, IN) and monoclonal antibodies against En (Gay et al. 1988), Arm (Peifer et al. 1992), and B-galactosidase (Promega) were performed as described in Noordermeer et al. (1992). Stained embryos were dehydrated and mounted for photography in methylsalicylate. Embryos were staged according to Wieschaus and Nüsslein-Volhard (1986).

For double stainings of embryos with anti-Wg and anti-En, embryos were stained overnight with both antibodies and then stained with goat anti-rabbit (Vector Laboratories) and developed with DAB (Sigma) to visualize Wg expression. A second overnight incubation with anti-en was followed by staining with horse anti-mouse antibody (Vector), with nickel $(1 \mathrm{mg} / \mathrm{ml})$ added to the $\mathrm{DAB}$ solution to yield a dark precipitate in the en-expressing cells.

Identification of mutant embryos in stainings for the Lab antigen was by visual inspection of the epidermis, which is highly abnormal by stages 13-15. wg and $d s h$ embryos are devoid of segment furrows and have abnormal head morphologies.

To identify $d s h$ mutant embryos unambiguously, females bearing germ-line clones of $d s h$ were crossed with males carrying on their balancer X-chromosome a fushi tarazu $(f t z)-l a c Z$ gene fusion (FM7, ftz-lacZ obtained from P. Gergen, SUNY, Stony Brook, NY). Staining with anti- $\beta$-gal antibody (Promega) identified the paternally rescued (wild-type) progeny by their $\mathrm{ftz}$ stripes. wg embryos were identified similarly by use of a hunchback ( $h b$ )- $\beta$-gal balancer in crosses among heterozygotes (van den Heuvel et al. 1993b).

For double stainings with anti-Wg and anti-En, embryos prior to stage 11 were identified genetically by the status of En antigen, which disappears by stage 10 in wg and $d s h$ mutants but remains until much later in wild type. From stage 11 , wg and $d s h$ mutants can be recognized morphologically, as the labial lobe does not develop.

\section{Mosaic analysis}

Germ-line clones were produced as described by Klingensmith et al. (1989) and Chou and Perrimon (1992). Embryonic gynandromorphs were among the progeny of ring- $X / Y$ males crossed to females bearing either $d s h$ or arm germ-line clones. Mosaic embryos were indicated by the presence of mutant and nonmutant denticles (as indicated by the denticle marker $s v b$ ) or by the presence of filzkörper material, which never develops in $d s h$ mutants.

Clones in adult structures were induced by mitotic recombination between heterozygous X chromosomes. Females heterozygous for a marked $(y w f) d s h$ allele were mated to males 
carrying a wild-type $\mathrm{X}$ chromosome. Progeny were irradiated $30-54 \mathrm{hr}$ after laying (first to second instar) at a constant dose of 1000 rads of X-rays. Control clones were induced in the progeny of matings between females homozygous for $y w f$ and wild-type males. Clones were scored on the dorsal thorax, head, legs, and wings under the dissecting microscope in $70 \%$ ethanol. Interesting specimens other than wings were dissected, incubated for $10 \mathrm{~min}$ in $10 \% \mathrm{KOH}$ at $60^{\circ} \mathrm{C}$, dehydrated, and mounted in Faure's mountant for viewing at higher magnification. Wings were dissected, dehydrated further, and mounted directly in Accumount (Baxter). Except in the eye, only clones showing the presence of $y$ and $f$ were considered, because distal crossovers between these markers might have eliminated the $d s h$ allele. In the mosaic analysis of the legs, we used topology along the dorsoventral axis and, when possible, bristle morphology to score for ventral or dorsal patterning. Compartments and bristle patterns in the leg are discussed in Struhl and Basler (1993) and references therein.

\section{Structural analysis of dsh genomic DNA}

Genomic DNA from adult females was purified as described by Finkelstein et al. (1990). We first screened $d s h$ alleles for structural differences in the $d s h$ region relative to each other and the control chromosome $F M 7 c$, with which the alleles were balanced. DNA was digested with SalI, HindIII, or EcoRI, electrophoresed, and Southern blotted. We used as probes a contiguous series of Sall fragments from the region of the chromosomal walk immediately distal to the hop gene. We found that $d s h^{v 26}$ contained a small deletion relative to isogenic controls [ $v 24$ and v145 (Geer et al. 1983) of $\sim 600$ bp within a $7.9-\mathrm{kb}$ SalI fragment, starting just distal to the PstI site $3.2 \mathrm{~kb}$ from the distal end and extending nearly to the $X$ hol site $0.65 \mathrm{~kb}$ farther proximal. Molecular techniques followed the protocols of Sambrook et al. (1989).

\section{cDNA isolation and analysis}

We used the $0.65-\mathrm{kb}$ PstI-XhoI fragment largely deleted in $d s h^{\text {v26 }}$ to screen a 9- to 12 -hr size-selected embryonic cDNA library (kindly provided by K. Zinn) as described by Finkelstein et al. (1990). The longest of 12 independently derived, related cDNAs was subcloned into pBSK (Stratagene) for sequencing and further analysis (pdc2.6). For in situ hybridizations, Ore- $R$ embryos were collected overnight, fixed, and hybridized as described Tautz and Pfeifle (1989). The probe used was a $0.65-\mathrm{kb}$ PstI-Xhol fragment derived from the $d s h$ cDNA. It was labeled via random priming using the Genius kit (Boehringer Mannheim). A negative control probe was a fragment derived from the vector plasmid $\mathrm{pBSK}$.

\section{DNA sequencing and sequence analysis}

For sequencing, nested deletions in both strands were made in pdc2.6 using exonuclease III (Erase-a-Base kit, Promega). Double-stranded plasmid was used as template DNA. We used the $\mathrm{T} 3$ and $\mathrm{T} 7$ primers for DNA synthesis with ${ }^{35} \mathrm{~S}$ and Sequenase (U.S. Biochemical Corp.) per the manufacturer's protocol. Sequence analysis utilized the GCG sequence analysis package (Devereux et al. 1984). Homology searches were performed using the BLAST (Altschul et al. 1990) and FAST (Lipman and Pearson 1985) algorithms on the GenBank, EMBL, and PIR data bases.

\section{P-element transformation and rescue}

We generated germ-line transformants carrying an ectopic copy of the $d s h$ region by cloning the $6.7-\mathrm{kb}$ SalI-XbaI fragment of pC5S8 (Fig. 6) into the P-element vector pCasper4 (Thummel et al. 1988) and injecting the plasmid into precellular blastoderm embryos using standard techniques (Spradling 1986). Twelve lines were obtained. Males from five lines in which the insert was autosomal were crossed to virgin females of the genotype $F M 7 / y w d s h^{v 26} f^{36 a}$. Each line rescued the mutant phenotypes of $d s h$.

Transformants carrying the $d s h$ cDNA under the control of a heat-inducible promoter were generated in the same manner, using as the injected material an EcoRI-EcoRV fragment of pdc2.6 (which contains the entire ORF) cloned into pCasperHS (C. Thummel, pers. comm.). Male transformants were crossed to virgin females bearing germ-line clones of $d s h^{v 26}$ marked with $s v b$. The presence of $d s h^{+}, s v b^{-}$larvae indicated rescue of all embryonic $d s h$ phenotypes.

\section{Acknowledgments}

We are grateful to T.-B. Chou, S. Panzer, M. van den Heuvel, P. Gergen, and J. Hall for providing fly stocks; to T. Kaufmann and C. Goodman for antibodies; to C. Thummel for plasmids; and to K. Zinn for a cDNA library. We especially thank R. Binari for providing the genomic DNA clones that span the $d s h$ region. S. Yanagawa and F. van Leeuwen helped in sequence confirmation. For antibody stainings we appreciate the advice of J. Noordermeer. Thanks go to D. Dang and M. Bienz for help with the initial staining and interpretation of Lab protein in $d s h$ embryos, respectively. R. Binari, E. Siegfried, J. Noordermeer, M. van den Heuvel, D. Sussman, D. Beier and S. Sokol kindly provided results prior to publication. J.K. was supported by a predoctoral fellowship from the Lucille P. Markey Charitable Trust. This work was supported by the National Institutes of Health grant (HD23684 to N.P.) and by the Howard Hughes Medical Institute. R.N. and N.P. are investigators of the Howard Hughes Medical Institute.

The publication costs of this article were defrayed in part by payment of page charges. This article must therefore be hereby marked "advertisement" in accordance with 18 USC section 1734 solely to indicate this fact.

\section{Note added in proof}

The sequence data for dishevelled has been deposited in the GenBank data library under accession number LZ6974.

\section{References}

Altschul, S., W. Gish, M. Webb, E. Myers, and D. Lipman. 1990. Basic local alignment search tool. J. Mol. Biol. 215: 403-410.

Babu, P. and S.G. Bhat. 1986. Autonomy of the wingless mutation in Drosophila melanogaster. Mol. Gen. Genet. 205: $483-486$.

Baker, N.E. 1988a. Embryonic and imaginal requirements for wingless, a segment polarity gene in Drosophila. Dev. Biol. 125: $96-108$.

- $1988 \mathrm{~b}$. Transcription of the segment polarity gene wingless in the imaginal discs of Drosophila, and the phenotype of a pupal-lethal wg mutation. Development 102: 489-498.

Bejsovec, A. and A. Martinez-Arias. 1991. Roles of wingless in patterning the larval epidermis of Drosophila. Development 113: $471-485$.

Binari, R. and N. Perrimon. 1994. Stripe-specific regulation of pair-rule genes by hopscotch, a putative Jak family tyrosine kinase in Drosophila. Genes ef Dev. (in press). 
Blair, S. 1992. shaggy (zeste-white 3) and the formation of supernumerary bristle precursors in the developing wing blade of Drosophila. Dev. Biol. 152: 263-278.

Bredt, D., P. Hwang, and S. Snyder. 1990. Localization of nitric oxide synthase indicating a neural role for nitric oxide. $\mathrm{Na}$ ture 47: 768-770.

Bredt, D., P. Hwang, C. Glatt, C. Lowenstein, R. Reed, and S. Snyder. 1991. Cloned and expressed nitric oxide syntase structurally resembles cytochrome $\mathrm{P}-450$ reductase. Nature 351: 714-718.

Bryant, P. and D. Woods. 1992. Letter to the editor. Cell 68: $621-622$.

Cavener, D. 1987. Comparison of the consensus sequence flanking translational start sites in Drosophila vertebrates. $\mathrm{Nu}$ cleic Acids Res. 4: 1353-1361.

Cho, K., C.A. Hunt, and M.B. Kennedy. 1992. The rat brain postsynaptic density fraction contains a homolog of the Drosophila discs-large tumor suppressor protein. Neuron 9: 929-942.

Chou, T.B. and N. Perrimon. 1992. Use of a yeast site-specific specific recombinase to produce female germline chimeras in Drosophila. Genetics 131: 643-653.

Couso, J.P., M. Bate, and A. Martinez-Arias. 1993. A winglessdependent polar coordinate system in Drosophila imaginal discs. Science 259: 484-489.

Cumberledge, S. and M. Krasnow. 1993. Reconstitution in vitro of a signaling system in Drosophila segmentation. Nature 363: $549-552$.

Devereux, J., M. Haebreli, and O. Smithies. 1984. A comprehensive set of sequence analysis programs for the VAX. Nucleic Acid Res. 12: 387-395.

DiNardo, S., E. Sher, J. Heemskerk-Jongens, J.A. Kassis, and P.H. O'Farrell. 1988. Two-tiered regulation of spatially patterned engrailed gene expression during Drosophila embryogenesis. Nature 332: 604-609.

Dougan, S. and S. DiNardo. 1992. Drosophila wingless generates cell type diversity among engrailed expressing cells. $\mathrm{Na}$ ture 360: 347-349.

Finkelstein, R., D. Smouse, J.M. Capaci, A. Spradling, and N. Perrimon. 1990. The orthodenticle gene encodes a novel homeo domain protein involved in the development of the Drosophila nervous system and ocellar visual structures. Genes \& Dev. 4: 1516-1527.

French, V. 1978. Intercalary regeneration around the segments of the cockroach leg. J.E.E.M. 47: 53-84.

French, V., P. Bryant, and S. Bryant. 1976. Pattern regulation in epimorphic fields. Science 193: 969-981.

Gay, N.J., S.J. Poole, and T.B. Kornberg. 1988. The Drosophila engrailed protein is phosphorylated by a serine-specific kinase. Nucleic Acids Res. 16: 6637-6647.

Geer, B., T. Lischwe, and K. Murphy. 1983. Male fertility in Drosophila melanogaster: Genetics of the vermillion region. J. Exp. Zool. 225: 107-118.

Gergen, P. and E.H. Wieschaus. 1986. Localized requirements for gene activity in segmentation of Drosophila embryos: Analysis of armadillo, fused, giant and unpaired mutations in mosaic embryos. Wilhelm Roux's Arch. Dev. Biol. 195: 49-62.

Gonzalez, F., L. Swales, A. Bejsovec, H. Skaer, and A. MartinezArias. 1991. Secretion and movement of the wingless protein in the epidermis of the Drosophila embryo. Mech. Dev. 35: 43-54.

Hartenstein, V. and J. Posakony. 1989. Development of adult sensilla on the wing and notum of Drosophila melanogaster. Development 107: 389-405.

Heemskerk, J., S. DiNardo, R. Kostriken, and P. O'Farrell. 1991.
Multiple modes of engrailed regulation in the progression toward cell fate determination. Nature 352: 404-410.

Heitzler, P. and P. Simpson. 1991. The choice of cell fate in the epidermis of Drosophila. Cell 64: 1083-1092.

Immergluck, K., P. Lawrence, and M. Bienz. 1990. Induction across germ layers in Drosophila mediated by a genetic cascade. Cell 62: 261-268.

Klingensmith, J. and N. Perrimon. 1991. Segment polarity genes and intercellular communication in Drosophila. In $A d$ vances in regulation and cell growth, Vol. 2; Cell activation: Genetic approaches (ed. James Mond, John C. Cambier, and Arthur Wiess|, pp. 251-274. Raven Press, Ltd., New York.

Klingensmith, J., E. Noll, and N. Perrimon. 1989. The segment polarity phenotype of Drosophila involves differential tendencies toward transformation and cell death. Dev. Biol. 134: 130-145.

Kyte, J. and R.F. Doolittle. 1982. A simple method for displaying the hydropathic character of a protein. J. Mol. Biol. 157: 133148.

Lindsley, D.L. and E.H. Grell. 1968. Genetic variations of Drosophila melanogaster. Carnegie Institution of Washington. Publ. 627.

Lipman, D. and W. Pearson. 1985. Rapid and sensitive protein similarity searches. Science 227: 1435-1441.

Martinez-Arias, A., N. Baker, and P.W. Ingham. 1988. Role of segment polarity genes in the definition and maintenance of cell states in the Drosophila embryo. Development 103: $157-170$.

Mitchell, H.K., J. Roach, and N.S. Peterson. 1983. The morphogenesis of cell hairs on Drosophila wings. Dev. Biol. 95: 387398.

Morata, G. and P.A. Lawrence. 1977. The development of wingless, a homeotic mutation of Drosophila. Dev. Biol. 56: 227240.

Noordermeer, J., P. Johnston, F. Rijsewijk, R. Nusse, and P. Lawrence. 1992. The consequences of ubiquitous expression of the wingless gene in the Drosophila embryo. Development 116: 711-719.

Noordermeer, J., J. Klingensmith, N. Perrimon, and R. Nusse. 1994. Armadillo and dishevelled function downstream of wingless in segmentation. Nature (in press).

Nusse, R. and H. Varmus. 1992. Wht genes. Cell 69: 1073-1087.

O'Brochta, D. and P. Bryant. 1985. A zone of the non-proliferating cells at a lineage restriction boundary in Drosophila. Nature 313: 138-141.

Peifer, M., C. Rauskolb, M. Williams, B. Riggleman, and E. Wieschaus. 1991. The segment polarity gene armadillo interacts with the wingless signaling pathway in both embryonic and adult pattern formation. Development 111: 1029-1043.

Peifer, M. and A. Bejsovec. 1992. Knowing your neighbors: Cell interactions determine intrasegmental patterning in Drosophila. Trends Genet. 8: 243-249.

Peifer, M., P. McCrea, K. Green, E. Wieschaus, and B. Gumbiner. 1992. The vertebrate adhesive junction proteins $\beta$-catenin and plakoglobin and the Drosophila segment polarity gene armadillo form a multi-gene family with similar properties. J. Cell Biol. 118: 681-691.

Perrimon, N. and A.P. Mahowald. 1987. Multiple functions of segment polarity genes in Drosophila. Dev. Biol. 119: 587600.

Perrimon, N. and D. Smouse. 1989. Multiple functions of a Drosophila homeotic gene, zeste-white 3, during segmentation and neurogenesis. Dev. Biol. 135: 287-305.

Perrimon, N., L. Engstrom, and A.P. Mahowald. 1989. Zygotic lethals with specific maternal effect phenotypes in Drosophila melanogaster: I. Loci on the X-chromosome. Genetics 
121: 333-352.

Phillips, R.G. and J.R.S. Whittle. 1993. wingless expression mediates specification of peripheral nervous system elements in late stages of Drosophila wing disc development. Development 118: 427-438.

Poodry, C. 1980. Epidermis: Morphology and development. In Genetics and biology of Drosophila. (ed. M. Ashburner and T.R.F. Wright), vol 2d, chap. 36. Academic Press, New York.

Rao, J.K.M. and P. Argos. 1986. A conformational preference parameter to predict helices in integral membrane proteins. Biochim. Biophys. Acta. 869: 197-214.

Reuter, R. 1990. Homeotic genes regulate the spatial expression of putative growth factors in the visceral mesoderm of Drosophila embryos. Development 110: 1031-1040.

Riggleman, R., P. Schedl, and E. Wieschaus. 1990. Spatial expression of the Drosophila segment polarity gene armadillo is post-transcriptionally regulated by wingless. Cell 63: 549 560.

Rijsewijk, F., M. Schuermann, E. Wagenaar, P. Parren, D. Weigel, and R. Nusse. 1987. The Drosophila homolog of the mouse mammary oncogene int-1 is identical to the segment polarity gene wingless. Cell 50: 649-657.

Rogers, S., R. Wells, and M. Rechsteiner. 1986. Amino acid sequences common to rapidly degraded proteins: The PEST hypothesis. Science 234: 364-368.

Ruel, L., M. Bourouis, P. Heitzler, V. Pantesco, and P. Simpson. 1993. Drosophila shaggy kinase and rat glycogen synthase kinase- 3 have conserved activities and act downstream of Notch. Nature 362: 557-559.

Ruff, P., D.W. Speicher, and A. Husain-Chishti. 1991. Molecular identification of a major palmitoylated erythrocyte membrane protein containing the src homology 3 motif. Proc. Natl. Acad. Sci. 88: 6595-6599.

Sambrook, J., E.F. Fritsch, and T. Maniatis. 1989. Molecular cloning: A laboratory manual. Cold Spring Harbor Laboratory Press, Cold Spring Harbor, New York.

Siegfried, E., L. Perkins, T. Capaci, and N. Perrimon. 1990. Putative protein kinase products of the Drosophila segment polarity gene zeste-white 3. Nature 345: 825-829.

Siegfried, E., T.B. Chou, and N. Perrimon. 1992. Wingless signaling acts through zeste-white 3 , the Drosophila homolog of glycogen synthase kinase-3 to regulate engrailed and establish cell fate. Cell 71: 1167-1179.

Siegfried, E., E.L. Wilder, and N. Perrimon. 1994. Components of wingless signaling in Drosophila. Nature (in press).

Simpson, P., M. El Messel, J. Moscoso Del Prado, and P. Ripollo. 1988. Stripes of positional homologies across the wing blade of Drosophila melanogaster. Development 103: 391-401.

Spradling, A. 1986. P-element mediated transformation in Drosophila: A practical approach (ed. D.B. Roberts), ILR Press, Oxford.

Struhl, G. and K. Basler. 1993. Organizing activity of wingless protein in Drosophila. Cell 72: 527-540.

Tautz, D. and C. Pfeifle. 1989. A non-radioactive in situ hybridization mehtod for the localization of specific RNAs in Drosophila embryos reveals translationa control of the segmentation gene hunchback. Chromosoma 98: 81-85.

Thummel, C.S., A.M. Boulet, and H.D. Lipshitz. 1988. Vectors for Drosophila P-element mediated transformation and tissue culture transfection. Gene 74: 445-456.

van den Heuvel, M., R. Nusse, P. Johnston, and P. Lawrence. 1989. Distribution of the wingless gene product in Drosophila embryos: A protein involved in cell-cell communication. Cell 59: 739-749.

van den Heuvel, M., J. Klingensmith, N. Perrimon, and R. Nusse. 1993a. Cell patterning in the Drosophila embryo:
Distribution of Wingless and Engrailed proteins in segment polarity mutants. Development (suppl.) (in press).

van den Heuvel, M., C. Harryman-Samos, J. Klingensmith, N. Perrimon, and R. Nusse. 1993b. Mutations in the segment polarity genes wingless and porcupine impair secretion of the wingless protein. EMBO J. 12: 5293-5302.

Wharton, K., B. Yedvobnick, V. Finnerty, and S. Artavanis-Tsakonis. 1985. opa: A novel family of transcribed repeats shared by the Notch locus and other developmentally regulated loci in Drosophila melanogaster. Cell 43: 567-581.

Wieschaus, E. and C. Nüsslein-Volhard. 1986. Looking at embryos. A practical approach (ed. D.B. Roberts), IRL Press, Oxford.

Wieschaus, E. and R. Riggleman. 1987. Autonomous requirements for the segment polarity gene armadillo during Drosophila embryogenesis. Cell 49: 177-184.

Woods, D.F. and P.J. Bryant. 1989. Molecular cloning of the lethal (1) discs large-1 oncogene of Drosophila. Dev. Biol. 134: 222-235.

1991. The Discs-Large tumor suppressor gene of Drosophila encodes a guanylate kinase homolog localized at septate junctions. Cell 66: 451-464. 


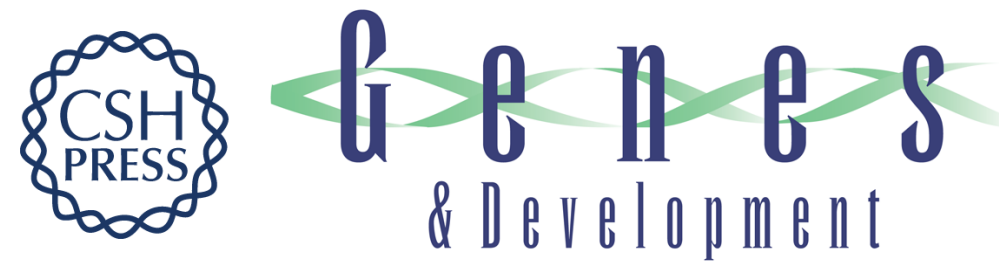

\section{The Drosophila segment polarity gene dishevelled encodes a novel protein required for response to the wingless signal.}

$\mathrm{J}$ Klingensmith, R Nusse and $\mathrm{N}$ Perrimon

Genes Dev. 1994, 8:

Access the most recent version at doi:10.1101/gad.8.1.118

References This article cites 63 articles, 18 of which can be accessed free at:

http://genesdev.cshlp.org/content/8/1/118.full.html\#ref-list-1

License

Email Alerting

Service

Receive free email alerts when new articles cite this article - sign up in the box at the top right corner of the article or click here.

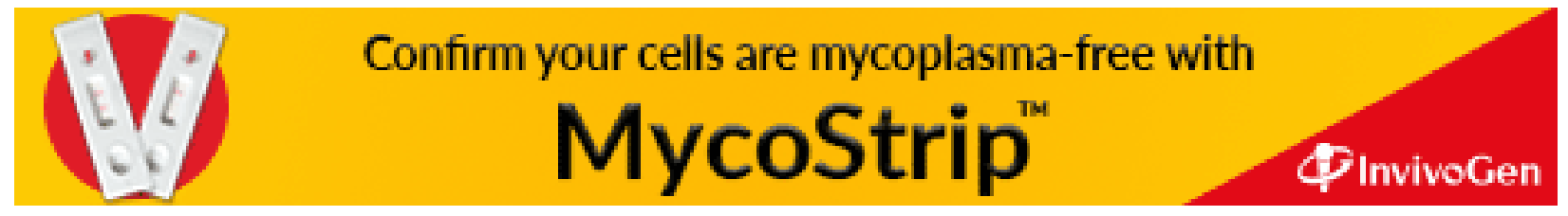

